\title{
Uso de crack e outras drogas: percepção familiar em relação à rede de suporte em um centro de referência
}

\author{
The use of crack and other drugs: the perception of family \\ members in relation to the support network in a reference center
}

Bruno David Henriques ${ }^{1}$

Amanda Márcia dos Santos Reinaldo ${ }^{2}$

Lilian Fernandes Arial Ayres ${ }^{1}$

Marina Silva de Lucca ${ }^{1}$

Regina Lunardi Rocha ${ }^{2}$

${ }^{1}$ Departamento de Medicina e Enfermagem, Universidade Federal de Viçosa. Av. PH Rolfs, Centro. 39100-000 Viçosa MG Brasil.

bruno.david@ufv.br

${ }^{2}$ Escola de Enfermagem, Universidade Federal

de Minas Gerais. Belo

Horizonte MG Brasil.
Abstract The abuse of psychoactive drugs is a health problem throughout the entire world, as its magnitude pervades childhood and adult life. The objective of this article is to understand the feelings and perceptions of family members regarding the support network, care and treatment of their offspring who use crack and associated drugs, in the context of a reference center for treatment. In line with methodological approach, qualitative research was used, with data collected and analyzed under the light of Phenomenology. The research was conducted at Belo Horizonte's CERSAMi in the State of Minas Gerais, Brazil. Eleven participants were interviewed, their participation being finalized at saturation point. The analysis was founded on three steps: description, reduction and phenomenological comprehension. Proposal for the work: the foundation, the presentation and the discussion are founded in the category Feelings and perceptions of family members in relation to the network for support, care and treatment. In the encounter with the subjects and during their immersion in discourse, moments which make family structure fragile are noticeable. In the dayto-day reality there becomes established a future of uncertainties in relation to the care, support and rehabilitation of the children.

Key words Crack cocaine, Family, Child, Adolescent, Qualitative research
Resumo O uso abusivo de substâncias psicoativas é um problema para a saúde em todo o mundo, pois possui ampla magnitude, na infância e na vida adulta. O objetivo deste artigo é compreender os sentimentos e as percepções dos familiares sobre a rede de apoio, cuidado e tratamento dos filhos usuários de crack e outras drogas acompanhados em um centro de referência. Como trajetória metodológica, foi utilizada a pesquisa qualitativa, com dados coletados e analisados à luz do referencial da Fenomenologia. A pesquisa foi realizada no CERSAMi de Belo Horizonte, Minas Gerais. Foram entrevistados 11 participantes, sendo a saturação o critério de finalização. A análise foi fundamentada em três etapas: a descrição, a redução e a compreensão fenomenológica. Os resultados evidenciaram categorias, cada qual, com seus temas de análise ou subcategorias. Como proposta para o trabalho, a fundamentação, a apresentação e a discussão estão fundamentadas na categoria: Sentimentos e percepções dos familiares em relação à rede de apoio, ao cuidado e ao tratamento. No encontro com os sujeitos e na imersão das falas, evidenciam-se momentos que fragilizam a estrutura da família. Na realidade diária se estabelece um futuro de incertezas em relação ao cuidado, ao apoio e à reabilitação dos filhos.

Palavras-chave Cocaina Crack, Família, Criança, Adolescente, Pesquisa Qualitativa 


\section{Introdução}

A sociedade vem passando por intensas transformações no campo da economia, da política e das relações sociais e culturais. Nesse contexto, a saúde não permaneceu fora do processo de mudança, apesar de sua singularidade e diversidade. Pensar em saúde significa promover a articulação entre setores da sociedade, possibilitar a reflexão das diversas áreas do conhecimento e estimular a corresponsabilidade entre a sociedade civil e o poder público para garantir a saúde como direito humano e de cidadania ${ }^{1}$.

No campo da saúde mental, as transformações também ocorrem com intensidade. Essa tendência de mudanças é evidenciada pela Organização Mundial de Saúde (OMS) ${ }^{2}$, que destaca a necessidade de tratar e acompanhar a população com transtornos psiquiátricos, oferecendo atendimento direcionado para os centros primários de base comunitária. É preciso resgatar e restabelecer a cidadania da pessoa em sofrimento mental, respeitando sua singularidade e subjetividade, tornando-o sujeito de seu próprio tratamento, sem a ideia de cura como o único horizonte. Espera-se, assim, que ocorra o fortalecimento da autonomia e a reintegração à família e à sociedade $^{3}$.

O processo de reestruturação da política de saúde mental fortalece a atenção primária e está orientado pelos princípios da reforma psiquiátrica brasileira. Esse movimento tem como objetivo melhorar a qualidade da assistência prestada, bem como favorecer o acesso da população que necessita de acompanhamento especializado, incluindo usuários de álcool, crack e outras drogas".

O uso abusivo de substâncias psicoativas é um problema para a saúde pública em todo o mundo, pois possui uma ampla magnitude, com diversas questões envolvidas. Destacam-se como fatores de risco os aspectos culturais, as relações interpessoais e as questões psicológicas e biológicas. Nesse contexto, os principais elementos são a disponibilidade da droga, as situações econômica e social desfavorecidas, os conflitos familiares graves, o baixo aproveitamento escolar, a atitude favorável em relação ao uso, o início precoce do uso, a suscetibilidade herdada em relação ao uso e a vulnerabilidade ao efeito das substâncias ${ }^{5}$. Como o modelo de assistência em saúde mental se encontra em processo de mudanças, é preciso discutir a necessidade de criação de novos serviços e o fortalecimento dos já existentes ${ }^{6,7}$.

No âmbito das estratégias foi implantado o Plano Emergencial de Ampliação do Acesso ao
Tratamento e Prevenção em Álcool e outras Drogas $(\mathrm{PEAD})^{6}$ 2009-2011. A proposta tem como objetivo intensificar, ampliar e diversificar as ações orientadas para prevenção, promoção da saúde, tratamento e redução dos riscos e danos associados ao consumo prejudicial de substâncias psicoativas. A estratégia vem para oferecer uma resposta adequada e sensível ao ambiente cultural, aos direitos humanos e às peculiaridades da complexa clínica no âmbito de álcool e drogas, associando-se, no plano intersetorial, às demais políticas geradoras de inclusão e cidadania.

Dentro das diretrizes do $\mathrm{PEAD}^{6}$, destaca-se a priorização de ações voltadas para crianças e adolescentes, pois o consumo de drogas ilícitas vem aumentando em todos os segmentos sociais, principalmente entre este grupo populacional. Nessa etapa existe a dicotomia entre a infância e a vida adulta: o jovem tem, em alguns casos, dificuldade em aceitar as orientações dos pais, em geral busca o controle de sua própria vida e se afasta da família "naturalmente". O adolescente tende a se aproximar de seus pares, e se esse grupo estiver fazendo uso de drogas ele pode se sentir pressionado a experimentar. A facilidade de acesso e o aparecimento de novas formas de comercialização, como o crack, farelo ou pó, de menor preço, contribuem para maior oferta, procura e prevalência da droga no mercado ${ }^{8,9}$.

O uso e o abuso de substâncias como o crack constituem um fenômeno complexo na infância e adolescência, acarretando consequências adversas na saúde do usuário e também no relacionamento, na integração familiar e no convívio social. Ao entrar em contato com as drogas nesse período de maior vulnerabilidade ele se expõe a riscos, sendo essa relação um fenômeno muito frequente, mas que por sua complexidade é difícil de ser abordada ${ }^{7}$. Tal situação passou a ser um desafio para a sociedade, consequentemente diferentes setores têm a responsabilidade de enfrentá-lo. A prevenção e o tratamento nessa faixa etária têm impacto concreto no futuro dos jovens, diminuindo o seu sofrimento e de seus familiares, além de possibilitar conquistas sociais em longo prazo ${ }^{10}$.

Portanto, essas fases devem ser destacadas, por serem momentos especiais e importantes na vida do indivíduo e de sua família. A reabilitação da criança ou do adolescente é fundamental. Paralelamente a essa questão, o impacto no núcleo familiar também deve ser observado com atenção e cuidado, pois muitas vezes a família não está incluída na abordagem e não recebe o suporte adequado da equipe de saúde, ou de 


\section{Trajetória metodológica}

Trata-se de um artigo extraído da Tese de Doutorado "Significados e vivências dos pais e responsáveis sobre o filho usuário de crack e outras drogas: uma abordagem

fenomenológica", desenvolvida no Programa de Pós-Graduação em Ciências da Saúde com área de concentração em Saúde da Criança e do Adolescente, da Faculdade de Medicina da Universidade Federal de Minas Gerais.

Para compreender as questões subjetivas envolvidas na temática, utilizou-se a abordagem qualitativa, que possui o enfoque teórico e o prático que se articulam constantemente. $\mathrm{O}$ que o pesquisador aprende sobre as observações empíricas na teoria, juntamente com as experiências vividas por ele, deve constituir o ponto de partida para o início dos trabalhos. Esse entendimento proporciona recursos para ver os objetos de sua percepção na sua origem social, histórica e de funcionamento ${ }^{11-13}$.

Partindo desses pressupostos, elegeu-se a fenomenologia como percurso metodológico, pois o objetivo foi compreender os sentimentos e percepções dos familiares sobre a rede de apoio, cuidado e tratamento dos filhos usuários de crack e outras drogas, buscando compreender a essência desse fenômeno.

A palavra fenomenologia deriva do grego: phainomenon (fenômeno), que significa aquilo que se mostra por si mesmo, e logos, que é o discurso que esclarece ${ }^{12}$. A fenomenologia surgiu e ganhou destaque com Edmund Husserl no começo do século XX, na Alemanha. Apresentava-se como um novo método destinado a fundamentar tanto a Filosofia, como as Ciências ${ }^{12,14}$.

A pesquisa fenomenológica está dirigida para significados, ou seja, demonstrações claras sobre as percepções que o indivíduo tem sobre o que está sendo pesquisado, que são expressas pelo sujeito que as percebe ${ }^{12,15}$. Nesse contexto, o sujeito é tido como uma pessoa que atribui significados,

e não um repetidor de ideias adquiridas de forma mecânica $^{14,16}$. $\mathrm{O}$ alvo é chegar às experiências $\mathrm{e}$ vivências que são atribuídas pelos sujeitos à situação que está sendo estudada. Os dados obtidos nas pesquisas são situações vividas descritas pelo sujeito $^{17,18}$.

A pesquisa foi realizada no Centro de Referência em Saúde Mental Infanto-Juvenil (CERSAMi) de Belo Horizonte, Minas Gerais. A unidade é responsável pelo atendimento e acompanhamento ambulatorial de crianças e adolescentes com transtornos mentais graves e/ou usuários de álcool e outras drogas. A proposta do cuidado está apoiada na terapêutica individualizada e coletiva, articulada com diferentes serviços extra -hospitalares, como Unidades de Atenção Primária (UAPS), ambulatórios pediátricos e leitos em hospitais gerais e outros dispositivos sociais ${ }^{19,20}$.

O trabalho contou com a participação de pais ou responsáveis legais de crianças e adolescentes que fazem uso de crack e outras drogas e são acompanhadas no CERSAMi. A seleção dos participantes foi realizada e determinada em reunião com a equipe do serviço e organizada pelo gerente da unidade. A proposta do trabalho foi apresentada a todos os membros responsáveis pelos atendimentos e fundamentados nos objetivos. Os técnicos de referência são profissionais de nível superior (psicólogos, terapeutas ocupacionais, assistentes sociais, enfermeiros e médicos, dentre outros), responsáveis pelo acompanhamento de determinado paciente no serviço, e identificaram os casos potenciais para que os familiares fossem entrevistados.

Posteriormente, foi realizado contato por telefone e agendado o dia e horário da entrevista. A determinação do local era sugerida pelo sujeito, sendo realizada em sua residência ou na sede do CERSAMi.

Antes de se iniciar as entrevistas foram explicados os objetivos do trabalho, relatando informações referentes à participação e informando que as falas seriam gravadas. Após o aceite, eles assinaram o Termo de Consentimento Livre e Esclarecido-TCLE. O trabalho foi aprovado no Comitê de Ética em Pesquisa (COEP) da Universidade Federal de Minas Gerais e pelo Comitê de Ética em Pesquisa (CEP) da Secretaria Municipal de Saúde da Prefeitura de Belo Horizonte, conforme Resolução 466/2012 do Conselho Nacional de Saúde ${ }^{21}$.

As entrevistas foram guiadas por uma única questão norteadora: Como é para você ter um fitho que faz uso de drogas? Foram transcritas imediatamente após sua realização. Nesse momento 
a concentração e a imersão no conteúdo foram cruciais. Cada gravação foi escutada atentamente, sendo as falas dos sujeitos transcritas na íntegra. Para fortalecimento do sigilo, os depoimentos foram identificados por siglas, contendo o início da palavra família e um número, exemplo: FAM 01.

No processo de análise, adotou-se como referência a análise da trajetória fenomenológica, descrita em três momentos, sugeridos por Martins e Bicudo ${ }^{12}$ a descrição, a redução fenomenológica e a compreensão fenomenológica para entender o fenômeno e atingir os objetivos propostos. Após avaliação dos dados, foram construídas categorias, cada qual, com seus temas de análise ou subcategorias que configuram a essência do significado dado pelos pais ou responsáveis ao uso de crack dos filhos.

Como proposta para o presente artigo, a descrição, a apresentação e a discussão dos resultados estão fundamentados na categoria: sentimentos e percepções de familiares em relação à rede de apoio, cuidado e tratamento, com seus respectivos temas de análise ou subcategorias: $\mathrm{O}$ despreparo familiar para lidar com o fenômeno das drogas; A importância do apoio familiar no enfrentamento das drogas; A insegurança relacionada à recuperação do filho; A dificuldade de superação da dependência; $\mathrm{O}$ tratamento com foco em medidas rígidas e disciplinares; A importância da atuação do CERSAMi no cuidado de crianças e adolescentes usuários de crack e outras drogas; Apoio das entidades não governamentais às famílias com crianças e adolescentes usuários de crack e outras drogas; A educação como fator de proteção; A religiosidade e a esperança na recuperação do filho.

Fundamentado na proposta de análise, foi dado início à compreensão e interpretação do fenômeno. Essa etapa caracteriza-se pela busca de conhecimentos, teorias e pressupostos sobre a relação existente entre a rede de apoio, cuidado e tratamento do uso de crack e outras drogas por crianças e adolescentes, na percepção dos pais e responsáveis.

\section{Resultados}

Sentimentos e percepções de familiares em relação à rede de apoio, cuidado e tratamento.

Para a elaboração e organização dessa categoria de análise, foram avaliadas as falas que confluíram para os aspectos relacionados à rede de apoio, de cuidado e de tratamento na percepção do familiar que possui um filho usuário de crack e ou- tras drogas. São evidenciados momentos que fragilizam a estrutura da família e se estabelece um futuro de incertezas em relação à situação de vida.

A organização dos depoimentos se estrutura em aspectos relevantes que norteiam a construção dos resultados, com destaque para o despreparo familiar para lidar com a dependência química, a importância desse espaço para recuperação do filho, a insegurança em relação ao tratamento associada e a dificuldade de superação da dependência.

Em determinados contextos de vida, os responsáveis destacam as medidas rígidas e disciplinares como a melhor opção de cuidado. Em contrapartida, o CERSAMi aparece como um espaço importante de reabilitação, em consonância com o apoio de outros dispositivos governamentais (ex. escola) e não governamentais. Paralelo a todo esse contexto, a religiosidade e a esperança se tornam âncoras na reabilitação dos filhos.

Fatores como a falta de informação para lidar com a dependência química são colocados pelo familiar 06. Em função dessa situação, o sentimento de insegurança surge com intensidade no relato da familiar 03 .

[...] saber que o filho está entrando nesse caminho sem ter uma preparação, que orientação tem para gente do que fazer nessa situação? Muitas vezes não temos o transporte para levar, não sabemos onde levar [...] as pessoas tomam medicação, mas só medicação... ajuda um pouco [...] a família precisa de um apoio [...] o que fazer, o motivo de ajudar, porque muitas vezes nos deparamos com uma situação e ficamos sem saber, sem ter reação [...] o tratamento é triste [...] apesar da medicação ele fica muito nervoso, agitado em ter que tomar a medicação [...] (FAM. 06).

[...] nunca você vai ter segurança total que parou [...] existe uma situação que você nunca terá certeza [...] se ele parou em definitivo [...] ele não saiu das drogas, ele está fugindo do mundo real [...] eu sinto é que ele vai voltar a usar a qualquer momento, mesmo usando a medicação [...] saiu usou droga e voltou pior [...] (FAM. 03).

Muito se tem pensado sobre os motivos que fazem com que determinados pacientes tenham maior ou menor sucesso no tratamento da dependência de drogas. Trata-se de um momento complexo, que também é permeado por limitações no cuidado, fatos expressos na fala a seguir.

[...] a pessoa quer e não tem como sair dessa situação, tentam sair, mas parece que a vontade e uma força chamam para aquilo, eles não conseguem largar [...] não conseguem ver um recurso, um retorno, para muitos é difícil [...] a pessoa tem 
que querer se esforçar para sair [...] com consequências piores, que causam danos que muitas vezes parecem irreversíveis [...] são pessoas sem expectativa de vida [...] (FAM. 06).

Diante do despreparo, da insegurança e das dificuldades de superar as barreiras da dependência química, algumas falas convergem para a necessidade de realização de tratamento adotando-se medidas rígidas e disciplinares.

[...] nunca vou ter certeza se o tratamento está sendo correto [...] é uma coisa que para mim não está seguro, teria que ser um tratamento mais rígido, a pessoa tinha que ficar afastado da família [...] sem proteção [...] ele sente muita proteção e faz o que quer [...] não estou vendo progressão nenhuma, ele não progrediu nada [...] o tratamento está fraco [...] se você continuar nessa vida, você não tem futuro [...] para você parar de usar droga, precisa ser mais duro [...] dependendo da clínica $e$ do jeito que está o tratamento, ele não progride (silêncio) não tem jeito de você progredir [...] ele fez um tratamento no CEPAI, por muito tempo ele resistiu à droga, você acredita nisso? Encorpou e foi trabalhar [...] Não vai ser só a medicação que vai tirá-lo, vai depender da força de vontade [...] O CEPAI (Centro Psíquico da Adolescência e da Infância) tem rigidez, mas eles internam e você tem que ficar 24 horas [...] o tratamento de lá foi mais rígido [...] ele sabia que poderia ficar preso, porque eles não liberam, acho que o medo dele foi maior [...] vou ter de internar em uma clínica (FAM. 03).

$\mathrm{O}$ apoio de outros membros da família no enfrentamento do problema também é considerado pelos pais e responsáveis, conforme relato do familiar 02 .

[...] onde eu moro, todos são da família, quem me ajuda mais é a minha irmã, é a minha irmã que ele obedece e respeita muito [...] tenho apoio da família [...] eles não me deixam, o tempo todo estão do meu lado [...] minha filha mesmo, tem a casa dela [...] mas ela está ficando todos esses dias na minha casa comigo, preocupada por eu estar dentro de casa sozinha [...] minha irmã que está correndo atrás de advogado e eles estão pagando [...] (FAM. 02).

O cuidado oferecido pelo CERSAMi aparece nas falas com intensidade. $\mathrm{O}$ serviço vem ao encontro das necessidades colocadas pelo uso de crack e outras drogas por crianças e adolescentes. Essa relevância é descrita nas falas dos pais e responsáveis.

[...] O CERSAMi foi bom no tratamento, atuaram como profissionais, o que foi necessário fazer [...] fizeram e deu tudo certinho, por isso ele está aqui hoje fazendo tratamento [...] o tratamen- to que ele recebeu dentro do CERSAMi, eu achei dentro das normas, atenderam e sempre me procuraram [...] perguntam como está a situação [...] (FAM. 06).

Associada às políticas públicas, a atuação das organizações não governamentais (ONGs) também aparece na configuração da rede de apoio.

[...] a ONG que os meninos ficam, se eu precisar de alguma coisa, se eu não tiver dinheiro de passagem eles me dão [...] Eu procuro a ONG para me orientar, inclusive eles até falaram comigo, para ir ao Juizado de Menor, conseguir um juiz [...] (FAM. 09).

A rede de apoio constituída pelas entidades religiosas também oferece um ambiente seguro, que proporciona o estabelecimento de vínculos e laços afetivos do indivíduo com a comunidade, inserindo pessoas que podem auxiliar no processo de reinserção social e convivência. Com a análise das falas, constatou-se que associado à fé existe um forte sentimento de esperança por parte dos pais e responsáveis com relação à recuperação dos filhos, conforme os relatos descritos a seguir.

[...] mas Deus me ajuda muito [...] Só orando e pedindo a Deus força para cuidar dele e dos meus filhos dentro de casa. Minha mãe dizia: Deus nunca dá uma cruz que não podemos carregar [...] Existe um Deus que nos fortalece, que nos liberta e vai curar a doença e a droga do meu filho [...] a única coisa que falo, é que tenho que agradecer muito a Deus, eu oro por eles todos os dias, eles tem me ajudado muito [...] mas o que eu queria mesmo era poder cuidar do meu filho, mas nesse momento não tem como não. Eu tenho esperança que meu filho vai ser alguém na vida, vai sair do acautelamento, vai ser um grande homem, vai poder trabalhar, ter uma família, o que passou, passou, deixa para trás, bola para frente [...] (FAM. 08).

[...] estou apostando em tudo para ele melhorar e mostrar para todos que ele é capaz de conseguir e ser feliz, ter uma vida normal, trabalhar direito, estudar, ter a família dele, é isso [...] já olhei, a pessoa que ele falou que estava devendo, já falaram que mataram a pessoa, ele não está correndo risco mais, agora tenho esperança [...] está melhorando, tenho certeza que vai melhorar [...] Só Deus, é indo na igreja, pedindo força para poder te manter, porque se não, você faz besteira, você tem que ter muita fé em Deus [...] (FAM. 09).

\section{Discussão}

A política atual para a área tem como proposta a organização das ações do Sistema Único de Saú- 
de, direcionadas pelas Redes de Atenção à Saúde (RAS). A discussão sobre as redes de apoio, cuidado e tratamento é transversal e intersetorial e é importante para a construção de um modelo que atenda às reais necessidades da população ${ }^{22}$.

Constata-se um vácuo na política relacionada ao tema em estudo, uma vez que questões operacionais de funcionamento da rede geram conflitos de diferentes ordens para definir qual a melhor maneira de abordar crianças e adolescentes que fazem uso abusivo de drogas.

Nesse contexto, dentro do eixo relacionado ao cuidado da PNAD, a Rede de Atenção Psicossocial (RAPS) está fundamentada na articulação dos serviços dos diferentes níveis de atenção e na lógica do trabalho interdisciplinar, rompendo com o sistema fragmentado do cuidado. A RAPS possui potencial em aspectos como a acessibilidade, o cuidado integral, a melhoria do sistema de saúde, a redução de custos e os impactos positivos na saúde das pessoas ${ }^{23}$.

A rede é composta de serviços e equipamentos diversos, como: os Centros de Atenção Psicossocial(CAPS), os Serviços Residenciais Terapêuticos (SRT), os Centros de Convivência e Cultura, as Unidades de Acolhimento (UA) e os leitos de atenção integral (em Hospitais Gerais, nos CAPS III), que em uma atuação integrada e articulada a outros setores podem melhorar a integralidade e eficiência do cuidado aos pacientes e às famílias ${ }^{23}$.

Entretanto, existem desafios para superar a fragmentação das ações mesmo com a proposta de integração. Para Costa et al..$^{22}$, há ausência de diálogo e interação entre os elementos que constituem a rede, ocorrendo uma polarização dos serviços em nível primário, secundário (ambulatórios) e terciário (hospitais), sem comunicação entre os diferentes pontos de atenção. Associada a essas questões, a articulação com outros setores, como Justiça e Educação, é limitada.

Portanto, para construir estratégias de enfrentamento do uso de crack e outras drogas entre crianças e adolescente é preciso implantar modelos de tratamento que levem em consideração a cobertura assistencial, o acesso, a melhoria da qualidade dos serviços existentes e o diálogo entre os atores, sujeitos e setores que compõem a RAPS. Além disso, é importante que os serviços se ocupem das famílias de forma sistemática, para facilitar tanto o acesso da população às unidades, quanto à informação.

A família se sente passiva, sozinha e impotente diante do familiar usuário de droga. Existe um sentimento de resignação em relação ao tratamento que se torna distante da realidade. A família sente que não há esperança. A impotência supera todas as estratégias de enfrentamento. Portanto, atuar nos aspectos relacionados ao empoderamento dos familiares com informações referentes à situação é fundamental ${ }^{24,25}$.

Para o Ministério da Saúde ${ }^{26}$, a dependência do crack e outras drogas é um transtorno heterogêneo, com impactos diversos na vida das pessoas, podendo ser observado em diferentes contextos e circunstâncias. Muitos consumidores de drogas não compartilham da expectativa e do desejo de abstinência e abandonam os serviços. Outros sequer procuram esses serviços para tratamento.

Diante da insegurança familiar, surge o sentimento de que não há perspectiva de recuperação. A adesão ao tratamento ou a práticas preventivas e de promoção é baixa, fato que não contribui para a inserção social e familiar do usuário. Em contrapartida, o familiar tem pouca ou nenhuma informação a respeito do manejo do usuário de drogas, tornando evidente o sentimento de insegurança, de incerteza da eficácia do tratamento e da compreensão da proposta terapêutica dos serviços ${ }^{27}$.

Os aspectos relacionados ao tratamento são diversos. Algumas variáveis são conhecidas: os pacientes vivem noção de tempo muito diferente, em decorrência do efeito da droga; o tipo de droga de abuso; a rede de suporte ou rede social; a proximidade geográfica e o acesso ao serviço de saúde; e o tempo de espera para atendimento ${ }^{27}$.

Todas as questões citadas desvelam o sentimento colocado diante das dificuldades de superação da dependência. O processo de recuperação não é tarefa fácil, não se trata única e exclusivamente de uma mudança de hábito. O cuidado oferecido pela rede deve ser integral, incluindo a família e suas necessidades, para não correr o risco de tratar a dependência dentro do consultório, como se fosse somente uma questão psicológica ou médica. Abordar os distintos problemas envolvidos é necessário, pois só assim é possível indicar o tratamento com cobertura específica das necessidades de cada paciente?

É importante avaliar o contexto e compreender a experiência de vida dessa mãe e sua famúlia em relação ao filho usuário, antes de questionar sua opção de busca pela internação. FAM.03 é viúva, mãe de quatro filhos, residente em casa simples com três cômodos, trabalha todos os dias, de 10 às 22 horas e tem renda mensal de um salário mínimo para a sobrevivência de toda a família. Em sua fala, ela expressa com veemência a necessidade de um tratamento ordenado por medidas 
rígidas, pois quando este tipo de tratamento foi oferecido, ela percebeu mudança de atitude do filho diante da vida, diferente do tratamento em que ele estava inserido no momento da coleta de dados da pesquisa.

Pinsky e Bessa ${ }^{28}$ relatam que em determinados casos a família busca tratamento fundamentado na internação, mas a conduta deve ser avaliada pela equipe de modo que o bem-estar do jovem seja preservado. Em contrapartida, a realidade social em que essa mãe está inserida tem de ser compreendida com outro olhar, pois só questionar e julgar o sentimento da necessidade de internação não é suficiente. A exposição dos outros filhos ao fenômeno da droga e as dificuldades econômicas e sociais, associadas à violência gerada pelo quadro, são elementos que não devem ser desprezados, uma vez que a busca pela internação é a única forma identificada por ela para proteção do bem-estar da família.

A família é o espaço indispensável para garantia da sobrevivência, do desenvolvimento e da proteção integral de filhos e demais membros que a compõem, independentemente do arranjo familiar ou do modo como vem se estruturando. Ela proporciona aportes afetivos e materiais necessários ao desenvolvimento e bem-estar dos seus componentes ${ }^{2}$.

A situação das famílias é também caracterizada por problemas sociais de diferentes ordens, entre eles o uso e o abuso de drogas. Este fato evidencia a necessidade de acompanhamento, bem como de desenvolvimento de perspectivas e abordagens que possibilitem o entendimento sobre o fenômeno abuso de drogas e sua repercussão na família, no sentido de desenvolver estratégias de apoio no âmbito intrafamiliar ${ }^{29}$.

A instituição familiar é considerada um dos elos mais fortes na cadeia que pode levar apoio para superação da dependência; a união familiar possibilita a resistência dos indivíduos a adversidades. $O$ resultado dessa interação é o estabelecimento de vínculo que possibilita a comunicação de um conjunto de normas, que em harmonia, podem gerar força, segurança e esperança na recuperação dos filhos ${ }^{24}$.

O CERSAMi é um serviço ambulatorial de atenção diária destinado a crianças e adolescentes com transtornos mentais. Possui capacidade técnica para desempenhar o papel de regulador da porta de entrada da rede assistencial no âmbito do seu território e/ou do módulo assistencial. Também é responsável por supervisionar e capacitar as equipes de atenção básica, os serviços e os programas de saúde mental no âmbito do seu território e/ou do módulo assistencial, na atenção à infância e adolescência ${ }^{23}$.

A assistência prestada está focada no atendimento individual, em grupos (psicoterapia, grupo operativo, atividades de suporte social, entre outros), em oficinas terapêuticas, em visitas e acompanhamento domiciliar, em atividades comunitárias com foco na integração da criança e do adolescente na família, na escola, na comunidade, ou em quaisquer outras formas de inserção social e no atendimento à família. Todas essas ações devem estar articuladas de forma intersetorial, principalmente com as áreas de assistência social, educação e justiça ${ }^{23}$.

Nesse sentido, a assistência aos usuários de crack e outras drogas deve ser oferecida em todos os níveis de atenção, privilegiando os cuidados em dispositivos extra-hospitalares. O CERSAMi é o principal aparelho para o atendimento dos dependentes químicos. Essa abordagem deve estar inserida e articulada à atuação da Estratégia de Saúde da Família, programa de Agentes Comunitários de Saúde e outros elementos que venham a compor a Rede do Sistema Único de Saúde.

O Ministério da Saúde ${ }^{26}$ também destaca a necessidade de aperfeiçoar a assistência dos casos de maior gravidade nos dispositivos de saúde que demandem cuidados mais específicos, principalmente para o atendimento de urgências, como os quadros de intoxicação ou abstinência grave, além de outros transtornos clínicos e psiquiátricos agudos decorrentes da dependência química.

Fundamentado nos relatos, o CERSAMi também se configura como um serviço relevante para a família. A potencialidade do serviço é evidente nas falas, portanto aperfeiçoar os objetivos do programa, qualificar o atendimento e expandir o número de unidades é um caminho importante para o enfrentamento do uso de crack e outras drogas entre crianças e adolescentes, tornando-o não só na política, mas um componente estratégico na vida das pessoas para consolidação da RAPS.

As ações de enfrentamento do avanço das drogas devem ser articuladas em diferentes locais por onde circulam as crianças e os adolescentes usuários. Essa atuação exige equipamentos flexíveis, abertos, articulados com outros pontos da rede de apoio, como a educação, o trabalho, a promoção e defesa social, dentre outros ${ }^{19}$.

Além da articulação dos dispositivos públicos, as organizações não governamentais aparecem como elemento importante no apoio às famílias. Esse momento é desvelado na fala de uma 
mãe que possui cinco filhos, sendo um acautelado em medida socioeducativa por uso drogas e envolvimento com o tráfico. Ela reside em casa simples, com três cômodos, em um aglomerado marcado pela vulnerabilidade social. Relata que o local não é adequado, mas não quer sair, pois se sente acolhida por membros da família e por uma ONG, que dá suporte educativo para os filhos, além de viabilizar meios de defesa e orientação jurídica do adolescente acautelado e fornecer vale-transporte para visitá-lo, pois ela vive da renda do programa Bolsa Família e não tem condições financeiras para custear esses gastos.

Essa interação entre poder público e organizações não governamentais é necessária. Ela pode, em cada local, constituir núcleos específicos de ação que se articulem com apoio mútuo, alimentando-se e gerindo-se como rede, que cria acessos variados, acolhe, encaminha, previne, trata, reconstrói existências, institui alternativas para pessoas que vivem em situação de vulnerabilidade e veem seus filhos sem perspectiva de futuro diante do convívio com cenas de uso de drogas $^{19,26}$.

Schenker e Minayo ${ }^{30}$ relatam que proteger é uma noção que faz parte do contexto das relações primárias e do universo semântico das políticas sociais. Significa, sobretudo, oferecer condições de crescimento e de desenvolvimento, de amparo e de fortalecimento da pessoa em formação. Para os familiares, a educação é um elemento essencial na proteção e prevenção do uso de drogas. Nesse processo, por agregar em seu interior a comunidade de pares e por ter fortes instrumentos de promoção da autoestima e do autodesenvolvimento em suas mãos, o ambiente educativo é fator importante para a qualidade de vida de crianças e jovens, além de potencializar as ações de enfrentamento do uso de drogas. Para que isso ocorra, é necessário que os professores estejam capacitados e o ambiente escolar protegido e seguro.

A relação entre religiosidade e drogas na população infanto-juvenil tem sido objeto de investigação em muitas pesquisas, pois para o adolescente tanto o envolvimento e a prática religiosa, quanto o uso de álcool e drogas são dimensões muito significativas de sua experiência pessoal e social. Essas dimensões têm significativo impacto sobre a saúde física e mental, os comportamentos de risco e o desenvolvimento psicossocial dessa população ${ }^{30}$.

A religiosidade e o desenvolvimento da espiritualidade estão relacionados à prevenção do consumo de crack e outras drogas e aparecem como um elemento facilitador para a recuperação dos dependentes. As pessoas que frequentam a igreja regularmente se sentem protegidas. O estímulo à prática religiosa é visto pela família como uma tentativa de amparo às relações familiares e uma forma de recuperação. A rede de apoio construída pela religião oferece um ambiente seguro que proporciona o estabelecimento de vínculos e laços afetivos do indivíduo com a comunidade ${ }^{4,7}$.

Essa interação possui potencial terapêutico, pois ajuda no processo de tratamento e está presente de forma significativa no processo de reinserção social, uma vez que possibilita a participação de novos atores que podem contribuir para o processo de reabilitação.A fé gera um sentimento de esperança, que se torna força motriz para o manejo do abuso da droga por parte dos familiares em seu contexto de vida ${ }^{4,7}$.

\section{Considerações finais}

O tema em questão tem características peculiares e está envolto em mitos, estigmas, preconceitos, tabus e dificuldades. Os relatos do estudo contribuíram para a construção do conhecimento sobre a temática sob a perspectiva dos pais. Por meio da análise proposta, foi possível identificar que as relações estabelecidas entre o uso de drogas, família e o poder público são um grande desafio a ser enfrentado e precisam ser repensadas.

As dificuldades para lidar com a situação são grandes. Os participantes descreveram questões relacionadas à rede de apoio e tratamento, apontando pontos positivos dessa articulação, com destaque para a atuação do CERSAMi no tratamento e no suporte à família; o amparo por parte de outros membros da família; o apoio das Organizações Não Governamentais, e a área da educação como capaz de gerar mudança na vida do filho. Esses pontos devem ser fortalecidos no trabalho em rede.

Os apontamentos dos pais devem ser ponto de pauta de ações intersetoriais para minimizar o sofrimento dessas pessoas e fortalecer o laço social com equipes e serviços da rede de atenção especializada em álcool e drogas e da rede de saúde, assistência social, justiça e segurança pública.

A escola foi reconhecida em alguns momentos como um lugar de produção de saúde e potencial para manter a criança e o adolescente longe da droga, para outros ela deveria ser um espaço de educação e cidadania, entretanto aparece como um local que pode oferecer risco, pois muitos jovens envolvidos com a droga iniciaram 
o consumo no ambiente escolar. Associados a essas questões, exemplos de dificuldades em acessar órgãos da Justiça, da Saúde e da Assistência Social também foram frequentes nos discursos.

A compreensão de todos os fatores evidenciados pode contribuir de forma eficaz e efetiva para o desenvolvimento de ações que tenham como foco as reais necessidades dos familiares.

\section{Colaboradores}

BD Henriques trabalhou na concepção, no delineamento, na análise na interpretação dos dados e na redação e revisão do artigo. AMS Reinaldo e RL Rocha trabalharam na concepção, no delineamento, na análise, na interpretação dos dados, na redação e revisão e por fim na aprovação da versão a ser publicada. LFA Ayres e MS Lucca trabalharam na redação e na revisão da versão a ser publicada. 


\section{Referências}

1. Brasil. Ministério da Saúde (MS). Política Nacional de Promoção da Saúde. Brasília: MS; 2014.

2. World Health Organization (WHO). The World Health Report. Mental Health: understanding, new hope. Geneva: WHO, 2001.

3. Belfer ML. Child and adolescent mental disorders: the magnitude of the problem across the globe. J Child Psychol Psychiatry 2008; 49(3):226-236.

4. Seleghim MR, Inoue KC, Santos JAT, Oliveira MLF. Aspectos da estrutura familiar de jovens usuários de crack: um estudo do genograma. Ciênc Cuid Saúde 2011; 10(4):795-802.

5. Mombelli MA, Marcon SS, Costa JB. Caracterização das internações psiquiátricas para desintoxicação de adolescentes dependentes químicos. Rev bras enferm 2010; 63(5):735-740.

6. Brasil. Portaria $n^{\circ} 1.190$, de 4 de junho de 2009. Institui o Plano Emergencial de Ampliação do Acesso ao Tratamento e Prevenção em Álcool e outras Drogas no Sistema Único de Saúde - SUS (PEAD 2009-2010) e define suas diretrizes gerais, ações e metas. Diário Oficial da União 2009; 5 jun.

7. Pinho LB, Oliveira IR, Cardozo-Gonzales RI, Harter J. Consumo de crack: repercusiones em la estructura y em la dinámica de las relaciones familiares. Enferm Glob 2012; 11(25):139-149.

8. Oliveira LG, Nappo AS. Caracterização da cultura de crack na cidade de São Paulo: padrão de uso controlado. Rev Saude Publica 2008; 42(4):664-671.

9. Moreira MR, Fernandes FMB, Ribeiro JM, Franco NTL. A review of Brazilian scientific output on crack contributions to the political agenda. Cien Saude Colet 2015; 20(4):1047-1062

10. Campos MLG, Ferriani MGC. Uso de drogas entre crianças de 6 a 7 anos de uma escola primária de Celaya, Guanajuato, México. Rev Latinoam Enferm 2008; 16(n. esp.):523-528.

11. Minayo MCS. O desafio do conhecimento: pesquisa qualitativa em saúde. 9a ed. São Paulo, Rio de Janeiro: Hucitec, Abrasco; 2006.

12. Martins J, Bicudo MAV. A pesquisa qualitativa em psicologia: fundamentos e recursos básicos. $5^{\mathrm{a}}$ ed. São Paulo: Centauro; 2005

13. Turato ER. Métodos qualitativos e quantitativos na área da saúde: definições, diferenças e seus objetos de pesquisa. Rev Saude Publica 2005; 39(3):507-514.

14. Capalbo C. Fenomenologia e ciências humanas. $3^{\mathrm{a}} \mathrm{ed}$. Londrina: UEL; 1996.

15. Dartingues A. O que é a fenomenologia. $7^{\mathrm{a}}$ ed. São Paulo: Moraes; 2000.

16. Bicudo MAV, Espósito VHC. Pesquisa qualitativa em educação. 2a ed. São Paulo: Ed. UNIMEP; 1997.

17. Spíndola T. A fenomenologia e a enfermagem: algumas reflexões. Rev Esc Enferm USP 1997; 31(3):403-409.

18. Horta LC. O significado do atendimento ao adolescente na Atenção Básica à saúde: uma análise compreensiva [dissertação]. Belo Horizonte: Universidade Federal de Minas Gerais; 2006.
19. Hoffmann MCCL, Santos DN, Mota ELA. Caracterização dos usuários e dos serviços prestados por Centros de Atenção Psicossocial Infanto-juvenil. Cad Saude Publica 2008; 24(3):633-642.

20. Jardim VMR, Cartana MHF, Kantorski LP, Quevedo ALA. Avaliação da política de saúde mental a partir dos projetos terapêuticos de Centros de Atenção Psicossocial. Texto \& contexto enferm 2009; 18(2):241-248.

21. Brasil. Resolução no466, de 10 de dezembro de 2012. Diretrizes e Normas Regulamentadoras de Pesquisas Envolvendo Seres Humanos. Diário Oficial da União 1996; 16 out.

22. Costa PHA, Mota DCB, Paiva FS, Ronzani TM. Desatando a trama das redes assistenciais sobre drogas: uma revisão narrativa da literatura. Cien Saude Colet 2015; 20(2):395-406.

23. Brasil. Portaria no 3.088, de 23 de dezembro de 2011. Institui a Rede de Atenção Psicossocial para pessoas com sofrimento ou transtorno mental e com necessidades decorrentes do uso de crack, álcool e outras drogas, no âmbito do Sistema Único de Saúde (SUS). Diário Oficial da União 2011; 24 dez.

24. Fergusson DM, Boden JM, Horwood LJ. The developmental antecedents of illicit drug use: evidence from a 25-year longitudinal study. Drug Alcohol Depend 2008; 96(1-2):65-177.

25. Gabatz RI, Schmidt AL, Terra MG, Padoin SM, Silva AA, Lacchini AJ. Perception of crack users in relation to use and treatment. Rev Gauch Enferm 2013; 34(1):140146.

26. Brasil. Ministério da Saúde (MS). A Política do Ministério da Saúde para Atenção Integral a Usuários de Álcool e outras Drogas. 2a ed. Brasília: MS; 2004.

27. Boyd CJ, Holmes C. Women who smoke crack and their family substance abuse problems. Health Care Women Int 2002; 23(6-7):576-586.

28. Pinsky I, Bessa MA. Adolescência e drogas. São Paulo: Contexto; 2004.

29. Kaloustian, SM. Família brasileira, a base de tudo. $10^{\mathrm{a}}$ ed. São Paulo: Cortez; 2011.

30. Schenker M, Minayo MCS. Fatores de risco e de proteção para o uso de drogas na adolescência. Cien Saude Colet 2005; 10(3):707-717.

Artigo apresentado em 12/01/2016

Aprovado em 07/11/2016

Versão final apresentada em 09/11/2016 